\title{
"A CADA UM CONVÉM UMA COISA": DEBATE E POLÊMICA EM TORNO DA SOCIOLINGUÍSTICA PARAMÉTRICA NA HISTÓRIA DA LINGUÍSTICA BRASILEIRA
}

\author{
Ronaldo de Oliveira BATISTA*
}

- RESUMO: Este artigo analisa um debate na linguística brasileira da década de 1980, quando Fernando Tarallo, José Borges Neto e Ana Lúcia de Paula Müller divergiram sobre a sociolinguística paramétrica. Na perspectiva de estudo da Historiografia da Linguística e a partir de um quadro sociorretórico de análise, que define diretrizes teórico-metodológicas desta proposta, o texto apresenta (i) considerações sobre o que se compreende nesta interpretação como retórica e (ii) uma análise historiográfica do debate. Esse olhar analítico considera para sua perspectiva interpretativa elementos discursivos dos discursos adotados no debate (ou seja, a retórica assumida pelos linguistas) e também elementos de natureza social, que podem circunscrever esses discursos em grupos específicos de pesquisadores em ciência da linguagem no Brasil. Aponta-se para o fato de que o debate em questão, diversas vezes referenciado quando se trata de uma história da linguística brasileira, manteve a sua natureza polêmica, evidenciando que a retórica dos linguistas, quando considerada pelo olhar historiográfico, deve ser compreendida a partir da sua inscrição social e histórica.

- PALAVRAS-CHAVE: Historiografia da linguística. Quadro sociorretórico. Retórica. Linguística brasileira. Sociolinguística parametrica.

\section{Introdução}

Este artigo apresenta uma narrativa histórica interpretativa de um episódio da linguística brasileira da década de 1980 por meio da análise de um debate entre Fernando Tarallo (1951-1992), José Borges Neto e Ana Lúcia de Paula Müller em torno do posicionamento dos linguistas em projetos de pesquisa e propostas teóricometodológicas. O corpus - os documentos históricos - são artigos publicados na revista DELTA, Documentação em Estudos Linguísticos Teóricos e Aplicados.

\footnotetext{
* Universidade Presbiteriana Mackenzie (UPM), Centro de Comunicação e Letras, São Paulo, São Paulo, Brasil. ronaldo.obatista@gmail.com. ORCID: 0000-0002-7216-9142
} 
Quadro 1 - Material de análise.

\begin{tabular}{|c|c|}
\hline AUTORES & ARTIGOS \\
\hline Tarallo, Fernando & Zelig: um camaleão-linguista. \\
& 1986. DELTA, 2: 1.127-144. \\
\hline Borges Neto, José; & Linguistas ou camaleões? Uma resposta \\
Müller, Ana Lúcia de Paula & a Tarallo. 1987. DELTA, 3: 1.85-95. \\
\hline Tarallo, Fernando & Uma estória muito mal contada. \\
& 1988. DELTA, 4: 2.265-272. \\
\hline
\end{tabular}

Fonte: Elaboração do autor.

Os textos do debate são analisados a partir de diretrizes metodológicas explicitadas na primeira seção deste texto, na perspectiva da Historiografia da Linguística (ALTMAN; BATISTA, 2012; BASTOS; BATISTA, 2016; BATISTA, 2013a, 2017b; SWIGGERS, 2004, 2012, 2013, 2017; KOERNER, 2014), que pode ser definida como o estudo sistemático, crítico e interpretativo da produção, do desenvolvimento e da repercussão de ideias linguísticas (o conhecimento elaborado sobre a linguagem e as línguas), propostas por agentes (circunscritos em grupos de especialidade ${ }^{1}$ ), em interação com a produção de outros agentes (com os quais se colocam em eixo de continuidade ou descontinuidade), situados em contextos sociais e culturais, em diálogo também com um horizonte de retrospecção e com demandas intelectuais, culturais, científicas, pedagógicas de um período histórico.

O historiógrafo da linguística, ao considerar seu objeto - a história do conhecimento produzido sobre a linguagem e as línguas -, tem como tarefa construir uma narrativa interpretativa sobre ideias e saberes. Para esse historiógrafo, a tarefa é não apenas contar o que um linguista ou um gramático (entre outros pensadores) considerou sobre a linguagem em sua obra, mas ir além da superfície dos documentos históricos (os textos produzidos sobre a linguagem) e chegar a uma perspectiva problematizadora, que terá como objetivo entender por que se pensou sobre a linguagem de determinado modo em uma época específica.

Essa perspectiva analítica considera como premissas:

a) os saberes não são desvinculados de uma camada contextual ${ }^{2}$, própria de um período histórico que legitima (ou não) reflexões sobre línguas e linguagem; os saberes estão circunscritos a comunidades argumentativas, isto é, todo linguista (ou outro pensador sobre a linguagem) se filia a uma corrente de pensamento de sua época ou de outras épocas, pertencendo, desse modo, a

Agentes são os autores que em um recorte histórico propuseram ideias sobre a linguagem. Grupos de especialidade são comunidades de pesquisadores que se reconhecem social e institucionalmente como membros que se articulam em torno de projetos de pesquisa específicos.

2 V. Swiggers $(2004,2017)$. O autor utiliza em espanhol o termo capas e em inglês o termo layer. A adoção, para o português, do termo camada foi discutida com Swiggers em 2016. 
grupos de especialidade, cujos membros compartilham da mesma ideia de como se deve entender a linguagem;

b) as ideias linguísticas pertencem a programas de investigação ${ }^{3}$, que se caracterizam pela visão geral do que é a linguagem (camada teórica) e também pelos métodos e técnicas (camada técnica) que empregam para descrever e analisar fenômenos linguísticos.

O interesse em resgatar a história do conhecimento sobre a linguagem tem crescido, inserindo a linguística em uma dimensão de reflexões históricas, não em movimento de resgate pela construção isolada de arquivos de memórias, sem conexão interpretativa com o presente, mas, pelo contrário, em um direcionamento em que estão em diálogo preocupações contemporâneas com indagações e soluções situadas em outros recortes temporais.

\section{A retórica dos linguistas}

Discursos científicos são manifestações linguísticas engajadas ideológica e socialmente, cujo objetivo é persuadir por meio da retórica ${ }^{4}$ que adotam ao defender ou negar ideias e saberes. Rajagopalan (2004) destaca que argumentos adotados em textos científicos estão elaborados em torno de estilos específicos para convencer, funcionando, portanto, como atos de fala, na nossa perspectiva em essência diretivos, já que pretendem levar o outro, sob a máscara da neutralidade objetiva da explicação científica, a aderir a um ponto de vista ${ }^{5}$.

\footnotetext{
O termo programas de investigação, de autoria de Pierre Swiggers, refere-se a tradições e paradigmas de pesquisa que se definem pela visão de língua e por conjuntos de procedimentos metodológicos específicos.

4 A discussão parte do sentido de retórica tal como atribuído por Murray (1994, p. 23) para o que ele define como retórica de ruptura: "'Revolutionary rhetoric' refers to claims (by group members) to major discontinuities, not to claims of persecution/rejection at the hands of an establishment. Choice of rhetoric (between a rhetoric of revolution and one of continuity) depends on the relative eliteness, professional age and access to recognition of group participants." Há abordagens de retórica, por exemplo, em Postal (1988, p. 129-137) e Koerner (2014, p. 175-220), utilizadas para observar aspectos epistemológicos ou históricos em trabalhos de linguística. Em nenhum desses três trabalhos, no entanto, há um interesse particular de conceitualizar e problematizar retórica como categoria de análise em estudos historiográficos. O sentido aqui atribuído à retórica também se relaciona com o sentido atribuído ao termo quando se pensa em produção discursiva ancorada em processos de persuasão. Assim, retórica relaciona-se aos discursos de cientistas e intelectuais que pretendem firmar uma posição por meio dos textos que elaboram ou proferem. Não se distancia, portanto, do sentido clássico que a palavra retórica assume como arte da persuasão, tal como explicitado, entre outros, por Reboul (2000) e Plantin (2008). Também empregamos retórica com o sentido de objeto de estudo a partir do qual se pode fazer uma observação analítica dos proferimentos científicos, tal como presente na área de estudo compreendida como "Retórica da Ciência", da qual Gross (1990) é um de seus representantes (confira também Malufe (1992) no contexto brasileiro). Essas considerações permitem que possamos de imediato conceitualizar nosso sentido de retórica de modo próximo ao da afirmação de Plantin (2008, p. 9): "Toda utilização estratégica de um sistema significante pode ser legitimamente considerada como uma retórica".

5 "Now, to regard science as an enterprise marked by controversies and constant clashes of opinion amongst researchers with conflicting and competing views is to admit that scientific research is over and above everything else a human affair." (RAJAGOPALAN, 2009, p. 435). Observar também a reflexão de Swiggers (2006, p. 27): "In short, metahistoriography is there to remind us that linguistic historiography, in its study of history of language study, finally has to delve into what science prefers to eschew, i.e. into what and how we are: Menschliches, Allzumenschliches."
} 
Nesse sentido, entra em destaque a dimensão histórica da ciência, na medida em que se considera, como objeto de análise, uma prática intelectual e social que é ação humana de um pesquisador ou pensador que atende a necessárias demandas da sociedade e dos espaços acadêmicos institucionais que ocupa.

Partindo dessas considerações, entendemos retórica em Historiografia da Linguística como uma manifestação discursiva de um agente da produção ou recepção de ideias linguísticas, circunscrito a um programa de investigação e a um grupo de especialidade ${ }^{6}$. Essa prática enunciativa se faz por meio de um gênero específico e de atos de fala que estabelecem rupturas ou continuidades em relação a paradigmas científicos e intelectuais no campo dos estudos da linguagem, pertencimentos ou exclusões em grupos de especialidade específicos, inseridos em um eixo histórico de desenvolvimento de ideias e saberes ${ }^{7}$.

Essa retórica, portanto, é de configuração complexa e contempla diferentes elementos que devem ser tomados como objetos de observação, uma vez que: a) a retórica se constrói em torno de diferentes estratégias argumentativas (seleção e elaboração de argumentos e seus modos de exposição) para persuadir os destinatários dos discursos que pretendem convencer sobre a legitimidade de saberes, técnicas, teorias e procedimentos metodológicos; nesse sentido ela diz respeito a argumentos que sustentam ideias linguísticas e que configuram a própria natureza de uma teoria a ser difundida, por exemplo; b) a retórica se desenvolve em uma rede de citações e alusões intertextuais que procuram validar ideias e saberes que são difundidos pelos meios discursivos e textuais empregados por um autor; nesse sentido ela diz respeito a uma ampla rede de citações e validações de conhecimento; c) a retórica contempla implícitos que articulam relações entre saberes em um eixo de diálogos entre tradições intelectuais e científicas; um autor se situa em comunidades argumentativas e em sua retórica leva em consideração pressupostos e subentendidos que estão na base do que afirma efetivamente; nesse sentido ela diz respeito aos implícitos que procuram persuadir os destinatários dos discursos.

Analisar o papel da retórica na legitimação de ideias linguísticas é tarefa a ser executada em meio aos procedimentos das fases heurística e hermenêutica (como em SWIGGERS, 2004), considerando que o objeto de análise será abordado a partir de um quadro sociorretórico ${ }^{8}$, por meio do qual se procura analisar os discursos em busca de convencimento e persuasão de um agente produtor e divulgador de conhecimento inserido num contexto histórico. Esse quadro de análise considera que os discursos

6 A retórica a que aqui se faz referência é o arranjo discursivo de natureza essencialmente histórica já que busca, por meio de diferentes estratégias persuasivas, a validação de um certo tipo de conhecimento situado em um determinado contexto intelectual e social. Sobre retórica em Historiografia da Linguística, v. Batista (2013b, 2015, 2016, 2017a).

7 A continuidade e a descontinuidade não são movimentos unilaterais ou excludentes. A continuidade muitas vezes está relacionada a progresso, melhoria ou acréscimo de ideias a outras ideias com as quais se coloca em relação de conjunção. E a descontinuidade é localizada, pois uma ruptura não é total com todos os saberes; quando se rejeita um saber, essa rejeição pode estar relacionada a outra tradição, continuidade, portanto, em outro ponto de vista.

8 Devo a Pierre Swiggers a sugestão do nome e a indicação a respeito de procedimentos adequados para a formulação da proposta de análise historiográfica. 
produzidos em situações específicas de interação verbal em torno da produção intelectual e científica no campo dos estudos da linguagem apresentam padrões que caracterizam, por sua vez, modos de interlocução e sua circunscrição social. Interessam a esse quadro, entendido como recurso analítico (ou ferramenta metodológica) para compreender elementos de uma história do conhecimento sobre a linguagem, tarefas do seguinte tipo: a) compreender como se constrói a legitimidade de um saber por meio do discurso adotado por agentes históricos da produção e recepção de ideias linguísticas; b) analisar recursos linguísticos e argumentativos utilizados na elaboração de retóricas de ruptura ou de continuidade; c) interpretar os saberes, e o discurso que veicula esses saberes, em sua circunscrição histórica, social e ideológica.

Em termos de procedimentos metodológicos na configuração do quadro sociorretórico, propõe-se que sejam considerados como focos de análise: a) contexto histórico e objetivos centrais de procedimentos argumentativos: análise do propósito central do documento em observação, com a descrição e interpretação do processo argumentativo empreendido pelo autor do documento, em conjunto com a circunscrição em programas de investigação, tradições de pensamento, grupos de especialidade, contextos intelectuais e/ou acadêmicos (consideração dos fatores externos que possibilitam a presença de um documento em uma dinâmica histórica); b) público e modos de divulgação: descrição dos receptores do documento (para quem se produziu determinado tipo de informação e quem se procura convencer de uma ideia e uma prática de descrição e análise) e dos mecanismos pelos quais ele se torna presente em um grupo (gêneros do discurso, tipos de abordagem). Refletir sobre esses aspectos permite que se aborde, por exemplo, a questão do argumento de influência nos estudos historiográficos; ${ }^{9}$ c) ethos: análise dos enunciadores de um documento e das imagens discursivas elaboradas dos sujeitos discursivos (inclusive dos receptores do texto), procurando evidenciar estratégias empregadas para estabelecimento de atos de fala na retórica dos linguistas; d) natureza das controvérsias científicas/intelectuais: a retórica que instaura oposições e descontinuidades pode ser analisada por meio de categorizações do tipo de controvérsias (discussão, disputa, controvérsia) que se estabelecem entre os agentes do conhecimento; e) polifonia: as vozes discursivas (em embate ou comunhão) que se deixam entrever nos discursos adotados por agentes produtores ou receptores de conhecimento, ou seja, observar de que modo redes de interlocução e horizontes de retrospecção auxiliam na legitimação de ideias linguísticas defendidas em retóricas específicas, uma vez que se considera que a retórica empregada reflete e recicla diferentes vozes de que se apropria, em diálogo com estratégias de argumentação, para alcançar legitimidade e validação de um posicionamento científico ou intelectual; f) estratégias de argumentação: os recursos argumentativos que sustentam e categorizam a

Batista $(2015,2016)$ aponta elementos externos que podem fazer parte do quadro de observação dos itens (a) e (b): clima de opinião em que programas de investigação são propostos; formação de grupos de especialidade e de pesquisadores; estabelecimento de círculos de interlocução; modos de comunicação e divulgação de saberes; institucionalização do conhecimento científico e intelectual; recepção que saberes obtiveram em meio ao processo de desenvolvimento dos estudos da linguagem; demandas sociais que incidem sobre a materialidade textual. 
retórica adotada: uso de argumentos de autoridade e referência a redes de interlocução; autopropaganda dos enunciadores; confronto entre vozes discursivas; desqualificação do oponente; seleção de lugares argumentativos ${ }^{10}$; emprego de exemplos e/ou dados de diferentes tipos; ironia; comparações, analogias e uso de metáforas; g) estrutura textual: análise de fatores linguísticos (lexicais, sintáticos, semânticos, pragmáticos, textuais) de composição do documento histórico que constituem a materialidade textual da retórica ${ }^{11}$.

Alguns desses aspectos - linguísticos e sociais - serão considerados na sequência deste artigo em relação a nosso corpus, analisado apenas em alguns dos possíveis temas que suscita para uma observação historiográfica.

\section{Tarallo vs. Borges e Müller: polêmica em torno da sociolinguística paramétrica}

Em 1986, o sociolinguista Fernando Tarallo publicou artigo no qual propunha cruzamento de modelos teóricos - em nome de "uma teoria global do discurso [que] pode e deve ser construída" (TARALLO, 1986, p. 127) - para análises de fenômenos linguísticos relacionados à sintaxe. Dessa postura advinha o título de seu artigo, "Zelig: um camaleão-linguista", referência a um episódio histórico e a um filme do diretor norte-americano Woody Allen.

A década de 20 deste século nos Estados Unidos presenciou um desafio à medicina e à psiquiatria na figura de Zelig: um camaleão humano, um mutante que adaptava sua forma física e sua personalidade às de outras pessoas com as quais travava contato. (TARALLO, 1986, p. 127).

Tarallo imprimiu a seu texto uma retórica de ruptura com a imagem científica de um linguista que, na sua interpretação, estaria por demais circunscrito a um programa de investigação, ou seja, a um modo de compreender a linguagem e de estabelecer seus métodos de seleção e análise. É pressuposto no trecho citado a seguir que há um comprometimento do pesquisador com um único programa de investigação que muitas vezes o impede de alcançar soluções satisfatórias para seus problemas de pesquisa.

10 Técnicas de argumentação conhecidas desde a Antiguidade Clássica Ocidental, constituem-se como premissas que buscam reforçar adesão a certos valores. O termo lugar é empregado desde os gregos para indicar locais virtuais nos quais os oradores pudessem acessar argumentos e colocá-los a sua disposição. Os lugares da argumentação definidos pela retórica clássica são: lugar de quantidade, lugar de qualidade, lugar de ordem, lugar de essência, lugar de pessoa, lugar do existente (PERELMAN; OLBRECHTS-TYTECA,1996; PLANTIN, 2008). Ainda, entende-se por lugar retórico: “[...] armazéns de argumentos, utilizados para estabelecer acordos com o auditório. O objetivo é indicar premissas de ordem ampla e geral, usadas para assegurar a adesão a determinados valores e, assim, re-hierarquizar as crenças do auditório." (FERREIRA, 2010, p. 69).

11 Batista $(2015,2016)$ indica uma série de elementos de natureza linguística que podem ser levados em conta nessa análise: temas e conteúdos proposicionais; seleções lexicais, construções sintático-semânticas, atos de fala; processos de sequencialização e referencialização que instauram objetos de discurso; modalizações; pressupostos e subentendidos; estilos de escrita. 
Em contrapartida, Tarallo propunha uma linguística aberta a diálogos entre propostas teórico-metodológicas para ampliar o poder analítico de fenômenos complexos: "restanos [...] chegar a um certo descomprometimento com o modelo em que atuamos e procurar, em sub-áreas afins, outras possíveis soluções [...]” (TARALLO, 1986, p. 142). Como estratégia argumentativa em seu texto, a seleção de um lugar de qualidade ${ }^{12}$ : aquele do linguista afeito a confluências, assumido pelo autor em seu discurso marcado pela subjetividade da primeira pessoa pronominal e pela seleção de adjetivos e advérbios.

$\mathrm{Na}$ perspectiva de Tarallo, o linguista restrito a uma única vertente de pesquisa poderia até inibir o progresso científico por conta de sua postura ortodoxa e pouco afeita à personalidade do camaleão, então considerado como o linguista aberto ao diálogo entre programas de investigação, não só os complementares (como ele parece indicar quando usa em seu texto a expressão "sub-áreas afins"), mas também entre aqueles que se distinguem radicalmente ${ }^{13}$.

Observe-se no fragmento abaixo também a presença de um pathos a motivar o leitor, incitando a um engajamento à proposta de um linguista plural, entendido, assim, como aquele mais apto a lidar com a complexidade dos fenômenos da linguagem humana. A proposta de Tarallo, ao mesmo tempo em que procurava persuadir o leitor pela elaboração simbólica de uma imagem positiva desse linguista plural, reforçava também o próprio ethos de Tarallo como esse cientista. O argumento se colocava, portanto, com uma força retórica inegável, com apelos a um lugar de qualidade retórico que estabelecia um ethos que incidia diretamente sobre a persuasão de um leitor que estivesse disposto a se engajar no novo em ciência da linguagem, tal como proposto no artigo, em meio à figura exótica do Zelig.

$\mathrm{O}$ argumento central do presente trabalho é, em síntese, uma proposta: a mesma ironia que marcou a vida de Zelig deveria, em princípio, subjazer à investigação linguística. Isto é, o linguista existente em nós deveria ser, na realidade, mais "zeligiano" que o pretendemos e o fazemos. Em outras palavras, uma certa dosagem de "falta" de personalidade acirradamente teórica poderá levar o linguista a resultados mais condizentes com os fatos que se propõe a analisar. (TARALLO, 1986, p. 129).

O propósito central do argumento do filme [o artigo em questão] será, portanto, não o de invalidar o trabalho já feito sobre o tópico em português, mas sim demonstrar que um pouco da doença do camaleão poderia salvar e salvaguardar a questão. (TARALLO, 1986, p. 131).

12 "Esse lugar retórico é muito comum nas propagandas, pois consiste na afirmação de que algo se impõe sobre os demais de sua espécie por ter mais qualidade, porque é único ou raro, original. $\mathrm{O}$ valor do único, do raro, expõe-se por sua oposição ao comum, ao vulgar, ao corriqueiro.” (FERREIRA, 2010, p. 71).

13 Essa proposta também está em Tarallo (1985). Nesse texto, o linguista indica a possibilidade de leituras paramétricas de trabalhos que já haviam sido realizados no âmbito teórico-metodológico de uma teoria da variação. (Agradeço ao(à) parecerista anônimo(a) a indicação desse texto.) 
Em sua retórica de ruptura, uma das práticas científicas, entendida como negativa, a combater era aquela colocada em ação pelos gerativistas. Para Tarallo, esses gerativistas representariam simbolicamente, em termos de retórica, o lugar da não qualidade, o que equivale ao da restrição teórica e, portanto, inadequado. Em contrapartida, o linguista camaleão deveria contemplar esse ortodoxo linguista gerativista, que passaria, então, a dialogar com os sociolinguistas em busca de explicações mais satisfatórias para análise de fenômenos sintáticos das línguas. Numa estrutura textual em paralelo, opondo gerativistas e sociolinguistas, a força argumentativa de Tarallo se construía em busca da fixação da imagem do linguista plural que sairia de uma ortodoxia e caminharia em direção a uma linguística mais social. Na elaboração do argumento, a balança pendeu para o lado da sociolinguística, que, sem dúvida, era alçada, na retórica, a uma dimensão positiva, exatamente por estar em seus domínios a possibilidade da confluência.

Como ponto de partida para sua própria reflexão, o historiador que tem o compromisso teórico de qualquer pesquisador com uma determinada linha de pesquisa fatalmente o [o linguista ortodoxo] condenará à condição de não-camaleão. Destes não-camaleões o historiador acredita serem os gerativistas o melhor exemplo.

A segunda personagem com que se deparará nosso historiador é o pesquisador preocupado com a realidade sócio-cultural-econômicalinguística. É o pesquisador que surgiu como consequência do desencanto com a escola gerativa. (TARALLO, 1986, p. 131-132).

Tudo aquilo que varia é, em geral, ignorado pelos gerativistas ou resolvido em termos de caráter da regra opcional. No modelo sociolinguístico de análise, no entanto, a variação e o aparente "caos" linguístico são assumidos como objeto de estudo e para a solução dos problemas de variação tem-se uma nova equação entre heterogeneidade e sistematicidade. (TARALLO, 1986, p. 132-133).

Em embate na retórica assumida pelo sociolinguista dois programas de investigação que adotavam visões distintas do que se entendia por língua. A delimitação teórica de cada campo se dava também orientada argumentativamente, pois o discurso assumido por Tarallo realçava o lugar de qualidade de uma linguística atenta à linguagem como fenômeno social e cultural, sem descuidar da análise de fenômenos de sistematicidade nas línguas.

Em nota ao final de seu texto, Tarallo informava que suas ideias tinham sido apresentadas em evento internacional dois anos antes, destacando nomes de linguistas reconhecidos (Gillian Sankoff, Eleonora da Motta Maia e Mary Kato) que leram e comentaram seu texto. Uma estratégia retórica que colocava suas ideias em um espaço de legitimação pelo uso do argumento de autoridade. 
De modo geral, a retórica do sociolinguista foi elaborada por meio de estratégias como o uso de: a) desqualificações de uma linguística limitada ao nível sentencial ou textual: "nossa doença anterior se explicava precisamente pelo caráter sentencial de nossos modelos gramaticais. A tal cura - da gramática da sentença para a do texto acabou por nos tornar mais 'doentes"'; b) questionamentos, já que seria mais adequada para a análise linguística uma proposta abrangente e plural; c) comparações, destacando o que seria positivo e o que seria, ao contrário, negativo; d) qualificação positiva do sujeito que enuncia a partir do lugar de qualidade assumido pelo sociolinguista.

O posicionamento de Tarallo (1986) deve ser compreendido a partir de uma perspectiva que ancora o linguista em um complexo programa de investigação o da sociolinguística em diálogo com a gramática gerativa - e em um grupo de especialidade - o dos sociolinguistas e gerativistas que consideravam válida a articulação teórico-metodológica entre a teoria da variação e mudança e a teoria de princípios e parâmetros. Estava em curso, na linguística brasileira da década de 1980, um ousado programa de investigação: a sociolinguística paramétrica ou variação paramétrica. Proposta considerada por muitos, não sem motivar o surgimento de críticas negativas ${ }^{14}$, como um dos raros momentos em que a linguística brasileira deu sinais de vitalidade ${ }^{15}$ e deixou de ser apenas ciência de recepção (fazendo eco à conhecida avaliação que Eugenio Coseriu (1980) fez da linguística latino-americana na década de 1970).

Essa sociolinguística paramétrica seguia de certo modo propostas dos linguistas Weinreich, Labov e Herzog, em "Empirical Foundations for a Theory of Language Change", de 1968 (com a ressalva de que os autores não propunham uma sociolinguística paramétrica no trabalho). Nesse texto, os linguistas argumentavam a favor da introdução de uma perspectiva teórica (capaz de analisar elementos estruturais e sistemáticos da língua) aliada a estudos da mudança.

$\mathrm{Na}$ linha de frente dessa proposta no Brasil, dois líderes intelectuais, Fernando Tarallo (sociolinguista) e Mary Kato (gerativista), que assumiam lugares opostos na retórica de ruptura de Tarallo, mas que depois se reconciliavam em confluência teórico-metodológica, cumprindo o objetivo da proposta: um programa conjunto entre a sociolinguística e a gramática gerativa na linha de princípios e parâmetros, apresentado programaticamente em 1989 com ares de novidade e ruptura em relação a um comportamento científico que recusava diálogos insuspeitados: "[...] polarizar uma linguística de regras [...], e uma ciência das probabilidades [...], tem marcado presença em todas as sub-áreas de investigação linguística há tempo até demais [...]

14 "Críticas à Sociolinguística Paramétrica emergiram, apontando a utilização simultânea de duas correntes teóricas opostas - cf., por exemplo, os ensaios de Borges Neto (2004).” (SILVA, 2013, p. 48).

15 “[...] Marcelo Módolo e Henrique Braga falam sobre algumas das teorias linguísticas desenvolvidas por pesquisadores brasileiros em nossa geografia nos últimos anos. Destacam [...] como 'propostas já estruturadas em terras brasílicas a Gramática construtural da língua portuguesa, de Back e Mattos (1972), a Sociolinguística paramétrica de Kato e Tarallo (1989), a Semântica de contextos e cenários de Ferrarezi Jr. (2010) e a Abordagem multissistêmica de Ataliba Teixeira de Castilho'." (BARONAS, 2012). 
essa polarização não só não é recente, como já nos estafou a todos." (TARALLO; KATO, 1989) ${ }^{16}$.

Uma proposta que, de acordo com o quadro analítico de Murray (1994), contava com ventos a favor, pois Tarallo e Mary Kato pertenciam a áreas institucionalizadas (sociolinguística e gramática gerativa), e ambos tinham na época boa repercussão de seus trabalhos. A proposta estava circunscrita principalmente, como núcleo difusor, a um centro de produção do conhecimento que era legitimado como tal, a Universidade Estadual de Campinas (Unicamp), um dos polos iniciais de produção linguística no Brasil (ALTMAN, 1998). A proposta nascia, assim, em espaço social e acadêmico de elite da pesquisa linguística brasileira, e, de fato, alcançou repercussão, pois diferentes pesquisas foram realizadas posteriormente no escopo do que propunha essa sociolinguística paramétrica (PARREIRA, 2015; SILVA, 2013).

A sociolinguista Maria Eugênia Duarte, da Universidade Federal do Rio de Janeiro, avaliou o papel de Tarallo nesse contexto, reforçando em seu ponto de vista, 29 anos depois do linguista camaleão, um papel de líder intelectual para o sociolinguista, considerado como propositor de um novo projeto de pesquisa, distante do que até então se havia visto para explicação de fenômenos sintáticos em mudança no português brasileiro:

A chegada de Fernando Tarallo ao Brasil, após seu doutorado na universidade da Pennsylvania (Philadelphia), em 1983, trazendo em sua bagagem, junto com os resultados de sua tese, o desejo de aplicar o modelo variacionista à análise de fenômenos sintáticos sugerindo mudança em curso no português brasileiro (PB) dentro do contexto das línguas românicas, levou-o inevitavelmente à busca de uma teoria que permitisse diagnosticar, nos fenômenos em variação no $\mathrm{PB}$, reflexos do que caracterizava os parâmetros propostos no âmbito da teoria gerativa. Tarallo sabia muito bem que, para entender as mudanças sintáticas atestadas na sua tese de 1983 e em diferentes estudos que ele e seus alunos viriam a desenvolver, não podia prescindir de uma teoria linguística que lhe oferecesse um meio de interpretar mudanças superficiais e associá-las a uma mudança subjacente mais abrangente. (DUARTE, 2015, p. 88).

Em revisão da presença da sociolinguística paramétrica na linguística brasileira, Duarte reforça os "frutos" que a proposta teria produzido, diante do número de trabalhos

16 “Tarallo e Kato, em 1989, são os primeiros estudiosos a apresentar a ideia de Chomsky como um possível caminho de resgate da compatibilidade existente entre as propriedades paramétricas do gerativismo e as probabilidades da teoria da variação. A tentativa, em seu trabalho, é comprovar seu reflexo ou realinhar tanto o modelo gerativo quanto o variacionista. [...] os autores propõem a Sociolinguística Paramétrica como uma possibilidade de estudo empírico do português - uma fonte de subsídios para uma linguística trans-sistêmica, partindo da tipologia do fenômeno VS encontrado em cada língua estudada, provedora de dados - tendo em vista a produtividade do fenômeno em cada língua." (PARREIRA, 2015, p. 352-353). 
resultantes da conjunção da teoria da variação e mudança com a teoria chomskiana de princípios e parâmetros.

O casamento, formalizado entre Tarallo e Kato (1989), viria a produzir frutos a partir de análises que permitiriam interpretar processos de mudança em curso no PB, entre os quais mudanças relacionadas ao quadro pronominal e à fixação da ordem SV, reunidas em Tarallo (1989; 1993) e em Kato e Tarallo (2003); efeitos da mudança na remarcação (parcial) do valor do Parâmetro do Sujeito nulo (Kato e Tarallo, 1986; Duarte, 1993, 1995), além de inúmeros estudos sincrônicos e diacrônicos que viriam a ser desenvolvidos sob a orientação ou inspiração de Tarallo e, posteriormente, de Kato (ver artigos em Roberts e Kato (1993) e Kato e Negrão (2000). (DUARTE, 2015, p. 89).

Contra o Tarallo de 1986, Borges Neto e Müller escreveram no ano seguinte, na mesma revista, o texto "Linguistas ou camaleão: uma resposta a Tarallo". Em tom de discórdia, os autores argumentavam (com base em Imre Lakatos e na incomensurabilidade) que a conjunção dos programas da sociolinguística e da gramática gerativa poderia colocar em risco o próprio fazer científico. Os autores instauraram outro lugar de qualidade: o da epistemologia e o do filosófo da ciência. Recurso a uma longa e legitimada tradição de conhecimento, tendo em vista desconstruir e negar como legítimo o que Tarallo propunha em seu texto.

Borges Neto e Müller desqualificaram em absoluto o Tarallo de 1986. Nos fragmentos abaixo, destacam-se em emprego de conotação negativa palavras como "discordar", "recomendar", "descomprometimento", “doença", "problemas", "sugestão". Itens lexicais que evidenciam o tom adotado na resposta à proposta de uma sociolinguística paramétrica. Como ponto principal a instaurar uma polêmica, a negação do argumento do outro como válido. Esse aspecto delineava uma retórica que estabelecia não mais um debate como espaço de troca de ideias, mas sim uma verdadeira interação polêmica que se colocava sem solução, uma vez que ambos os lados passariam a desvalorizar o argumento do outro, bem no espírito do que Amossy (2017) descreve como a retórica do dissenso ${ }^{17}$, fundada e estabelecida em uma interação que não se coloca em vias de resolução pacífica, em termos de concordância sobre posicionamentos e pontos de vista adotados por determinados enunciadores de um discurso.

O trabalho de Tarallo tem como objetivo recomendar um certo descomprometimento do linguista com o modelo em que atua, uma vez que é desejável uma certa quantidade de doença na pesquisa linguística para que esta se torne sã. (BORGES NETO; MÜLLER, 1987, p. 86).

17 “[...] a polêmica pública está indissoluvelmente ligada ao desacordo. É por isso que ela compartilha o descrédito que pesa sobre nossas sociedades sob as múltiplas formas do dissenso." (AMOSSY, 2017, p.17). 
Na medida, porém, em que se pretende adotar a mesma análise para os dados do português, aparecem problemas [...] (BORGES NETO; MÜLLER, 1987, p. 86).

Para Tarallo, estas dificuldades aparecem na medida em que, adotando a perspectiva do discurso, esquece-se dos fatos sintáticos; ou na medida em que se esqueçam os fatos discursivos quando adotada uma perspectiva puramente sintática para a análise dos dados.

O ponto central da argumentação de Tarallo, então, consiste na sugestão de que uma análise puramente sintática, bem como uma análise puramente discursiva, não se constituirão em análises satisfatórias dos fatos envolvidos em TOP e DESL.

Em outras palavras, a única saída é nos tornarmos, todos, camaleões.

[...] aparentemente, o camaleão de Tarallo é eclético, e é deste camaleão que gostaríamos de discordar. (BORGES NETO; MÜLLER, 1987, p. 87-88).

Os fragmentos abaixo nos mostram que a elaboração da retórica apoiava-se em argumentos de autoridade selecionados por Borges Neto e Müller. Observe-se o uso do léxico e de construções sintático-semânticas como: o uso de operador argumentativo de contrajunção em "constata, mas não compreende"; a desqualificação do outro na seleção lexical em "lhe falte fundamentação"; a reiteração de considerar o outro como equivocado no uso do advérbio "enganado novamente".

Nos fragmentos, pode-se observar também, em especial, o tom da polêmica sem solução no apontamento de uma possível falta de habilidade de Tarallo, resultante, como se depreende, de uma falha na formação intelectual do sociolinguista: o ethos do cientista competente e bem formado é negado, sendo negada consequentemente a validade de qualquer argumento que tenha sido exposto na proposição de um novo programa de investigação na linguística. Ao leitor, em meio à negação da validade da análise apresentada no primeiro texto de Tarallo (veja-se que é a própria competência do linguista que é questionada), são dirigidas, retoricamente (como efeito do discursivo), também paixões a provocar, ou não, adesão ao que Borges e Müller defendem.

Tarallo constata, mas não compreende porque talvez lhe falte uma fundamentação epistemológica, a postura não-camaleão do gerativista.

Enganado novamente por uma falsa imagem da ciência, Tarallo vai buscar nas atitudes individuais dos cientistas as razões para esse aparente desprezo dos gerativistas pelos "fatos" dos empiristas. 
Admitindo-se que a análise de Tarallo sobre a questão dos TOPs e DESLs em português seja correta, teríamos demonstrada a inadequação de ambos os programas (o gerativismo e a pragmática-discursiva) para o tratamento destes dados em português. Daí não decorre necessariamente que os programas devem ser abandonados [...], nem decorre a postulação de um maior despreendimento em relação aos modelos, como Tarallo faz crer. (BORGES NETO; MÜLLER, 1987, p. 91-92).

Na retórica de oposição que instaurou não verdadeiramente um debate mas uma polêmica (pautada na retórica do dissenso, de uma disputa sem possibilidade de solução, já que um assume indiscutivelmente seu espaço e posição discursiva em embate com o outro), também havia uma caracterização negativa de um suposto caráter cultural brasileiro, afeito ao ecletismo, segundo Borges Neto e Müller, pouco propenso, pelo que se pode compreender implicitamente, à rigidez das formulações científicas.

Além de não se justificar de um ponto de vista epistemológico, a recomendação de Tarallo tem o defeito de acirrar o caráter postiço da vida cultural brasileira. Neste sentido, a recomendação é duplamente danosa.

[...] O brasileiro sente-se justificado a trocar de ideologia como quem troca de roupa. Ele pode aceitar simultaneamente ideologias contrárias, desrespeitando-as em sua coerência original.

[...] se entendemos que o cientista vale por sua real contruibuição à compreensão de uma certa área do conhecimento e não por sua erudição, por seu domínio de várias teorias, é preciso que digamos NÃO ao linguista-camaleão porque ele não compreende as necessidades mais gerais de sua ciência e de sua cultura. (BORGES NETO; MÜLLER, 1987, p. 93-94).

A retórica de Borges Neto e Müller está essencialmente vinculada a um possível grupo de especialidade ainda não institucionalizado na linguística brasileira da década de 1980, já que pouco se falava e se produzia, no Brasil, em filosofia da linguística, articulada a uma filosofia da ciência, ou epistemologia da linguística.

Anos depois, os sociolinguistas que seguiram adiante com a sociolinguística paramétrica fizeram referência, em diferentes textos, à oposição ao linguista camaleão feita por Borges Neto e Müller:

A crítica mais veemente veio de Borges Neto, em 1988 e publicada em 2004, sobre a incomensurabilidade dos dois modelos teóricos - a 
teoria da Variação e Mudança - cujo pressuposto básico era a variação inerente ao sistema, interessada nos dados reais, e a teoria gerativa interessada no que era invariável no sistema e centrada no conhecimento do falante, tinha certa razão de ser: parecia mesmo uma heresia! Como compatibilizar teorias com objetos de interesse e pressupostos teóricos tão distintos? Dados empíricos de um lado e a busca da arquitetura da gramática universal de outro! (DUARTE, 2015, p. 89).

Diante da retórica de oposição de Borges Neto e Müller em 1987, Tarallo publicou uma tréplica em 1988 com "Uma estória mal-contada". No confronto estavam modos de compreensão do fazer científico, entre questões metodológicas e epistemológicas e entre a própria visão da prática de pesquisa.

Essas questões, no entanto, no julgamento histórico que hoje se pode fazer do debate, não foram levadas adiante, pois tanto a réplica quanto a tréplica se deixaram permear por discursos marcadamente legitimadores apenas dos seus próprios dizeres, sem, com isso, deixarem espaço aberto para o debate, contrariando o que a seção da revista assim nomeada poderia supor como discussão de ideias de natureza científica. Em vez de um debate, houve de fato polêmica sem solução.

Com voz beligerante e tom que não disfarçavam o descontentamento com a réplica que seu texto havia recebido, o Tarallo de 1988 alterou definitivamente o rumo do que se poderia esperar de um debate, transformando-o em uma polêmica que abandonava um espaço para discussão de ideias, como parecia ser a proposta da avaliação negativa feita por Borges Neto e Müller em 1987, ainda que esta também não se tenha pautado por estratégias que privilegiassem a discussão de ideias, uma vez que estava, a considerar a conceituação de Amossy (2017), essencialmente construída em torno do questionamento da validade do posicionamento do outro, instaurando o que já chamamos de retórica do dissenso.

O sociolinguista, dessa vez, assumiu uma retórica que consistiu essencialmente na desqualificação do outro como estratégia argumentativa. Tarallo, dando voz discursiva ao ethos do atacado, fez da adjetivação com conotação negativa a marca de um texto que colocava a questão como uma guerra de braços, ainda que Tarallo tenha dito em seu texto que não gostaria de gastar papel e tinta com uma questão a que parecia, no discurso, não dar relevância: "[...] ponderei, em um primeiro momento, não sacrificar papel e tinta na discussão de questões tão frugais quanto as levantadas na réplica." (TARALLO, 1988, p. 266).

[...] não uma tréplica a Borges Neto \& Müller pois, conforme relatarei, nada de substancial existe na réplica que mereça uma tréplica. Assim sendo, valho-me tão e unicamente de uma simples carta endereçada aos leitores, na qual desfaço os equívocos de leitura cometidos pelos autores da réplica. (TARALLO, 1988, p. 266). 
[...] desfazendo os mal-entendidos, com duas metas específicas em mente:

1. a de que o texto de 1986 sobre a longevidade do Zelig, isto é: do camaleão-linguista, é inquestionável, e

2. a de que a réplica de 1987, de tão inócua em propositura, nem mesmo escrita deveria ter sido. (TARALLO, 1988, p. 267).

Nas marcas textuais de uma retórica de recusa da validade do texto de Borges Neto e Müller (espelho invertido da retórica destes últimos, que também negava, em outra chave, a validade do Tarallo de 1986), a seleção lexical e o posicionamento marcadamente subjetivo do sociolinguista evidenciavam que a questão estava de todo modo distante do espaço de troca de ideias. Nesse sentido, destacam-se palavras e expressões como "arrogante", "pessoalmente agressivo", "altamente pretensioso", "lutam e gritam pela pureza epistemológica". Observe-se também o uso da ironia a descaracterizar a validade e consistência teórica do artigo de Borges Neto e Müller (1987): "ahá!, pela 'racionalidade da ciência"”.

[...] a revista D.E.L.T.A. publicou, em sua seção DEBATE um texto arrogante, pessoalmente agressivo, e altamente pretensioso, assinado por José Borges Neto e Ana Lúcia de Paula Müller [...] (TARALLO, 1988, p. 266).

[...] meu Zelig aparece como uma peça desprezível de uma engrenagem no meio da qual Borges Neto \& Müller desesperadamente lutam e gritam pela pureza epistemológica, e, ahá!, pela 'racionalidade da ciência'. (TARALLO, 1988, p. 268).

A retórica de Tarallo assumiu o lugar da oposição, em tom raivoso das polêmicas e discussões que não pretendem fazer avançar um debate, mas negar ao outro um lugar de qualidade de onde viria um discurso possível de ser contemporizado. A se destacar o posicionamento que implicitamente também negava valores intelectuais a Borges e Müller, vistos por Tarallo como incapazes de uma leitura adequada de seu texto. Mais uma vez, o espaço que se criou na retórica dos linguistas foi o da polêmica construída principalmente na negação do valor do outro.

Ao não haverem entendido uma simples metáfora como o Zelig [...], que, [...], se explica perfeitamente do ponto-de-vista da evolução da teoria da variação (os dois autores desconhecem a teoria da variação, sua evolução, e nem tampouco sua aproximação, em anos recentes, ao modelo gerativo) caíram em uma piada ainda maior: a apologia da ortodoxia cega, isto é: o dogmatismo. Isto se reflete em todas as decisões arbitrárias que os dois autores tomam ao longo do texto. (TARALLO, 1988, p. 269). 
[...] ignoram a análise dos dados, mesmo supondo (e eu diria, aceitando) que ela esteja correta (p. 92), exatamente a análise que demonstra que ser dogmático dentro da ciência (no caso específico, da teoria da variação) é uma atitude cientificamente incorreta. [...] Aliás, se os dois autores tivessem tido o cuidado de ler a literatura variacionista, teriam encontrado em Braga (1986) e nos resultados que a autora ali projeta para as mesmas construções, confirmação para as ressalvas que eu próprio havia levantado em meu texto de 1986. (TARALLO, 1988, p. 269).

Como no texto de 1986, Tarallo recorreu aos argumentos de autoridade, em busca da validação de sua proposta, que ele considerou, como é possível inferir pela retórica do sociolinguista, injustiçada e equivocadamente avaliada. Além da busca pela associação com o grande nome da sociolinguística, Tarallo, mais uma vez, advogava para si o lugar da qualidade, configurado pelo diálogo entre as ideias de Labov e as do linguista brasileiro.

A grande ironia disso tudo transparecerá agora quando, através de um texto recente de Labov (1987), do criador do modelo variacionista, se fizerem confirmar aquelas minhas colocações de 1986. Ou seja: mesmo sem o saber, eu antecipava no Zelig (1986), em um outro texto de 1986 [...], e ainda em Tarallo (1987), além de Kato e Tarallo (1987, 1988), tudo aquilo que o próprio Labov assumiria em relação à mudança intra-modelo sofrida pela teoria da variação, fato que, do ponto-de-vista de Borges Neto \& Müller, merece toda e qualquer apreciação positiva (referindo-se à CGT (Gramática Gerativa Transformacional) [...]. (TARALLO, 1988, p. 270).

A orientação dada por Tarallo a essa sua tréplica privilegiou algumas estratégias argumentativas para a elaboração de sua retórica de oposição e negação da validade da réplica de 1987: a) desqualificação do outro (por meio do uso de adjetivação e caracterização negativa); b) utilização de argumento de autoridade; c) revalorização do lugar de qualidade; c) citação de rede intertextual a elaborar um horizonte de retrospecção de qualidade; d) ironia e metáfora; e) aproximação com o leitor.

E com essa longa citação de Labov (1987) despeço-me de vocês, caros leitores. Nesse momento tão promissor da linguística em que o racionalismo chomskiano e o empirismo laboviano parecem se aproximar cada vez mais, a longevidade do Zelig é inquestionável. Coloco-me à disposição para quaisquer esclarecimentos e continuarei, com o maior prazer, esse debate tão saudável desde que não percamos tanto tempo com ideologias e nos concentremos cada vez mais na real e verdadeira pesquisa acadêmica sobre a linguagem. Um grande abraço do Zelig. (TARALLO, 1988, p. 271). 
Nesse jogo de forças que o debate se tornou, o encaminhamento da tréplica adquiriu contornos excessivamente pessoais e agressivos na negação da visão do outro, encerrando a série de publicações, sem manisfestação ou resposta por parte dos autores do texto de 1987, naquele contexto.

Após a tréplica de Tarallo em 1988, Borges Neto e Müller não se posicionaram novamente nas páginas de DELTA. Mesmo assim, um ano após a tréplica, Borges Neto, sem a companhia de Müller, retomava a questão nas páginas de outro periódico, associado à Universidade Federal do Paraná, instituição em que Borges Neto na época atuava. Esse texto de $1989^{18}$ reafirmou a avaliação negativa para a sociolinguística paramétrica, em um posicionamento retórico que negava, mais uma vez em absoluto, a junção das teorias: “[...] fica claro, então, que qualquer proposta de 'aproximação' de teorias distintas ou retoma os postulados neopositivistas ou encontra na questão da incomensuralibilidade uma barreira formidável [...]" (BORGES NETO, 2004, p. 199).

Pelo visto, pode-se entender que o debate Tarallo vs. Borges e Müller caracterizase como uma interação polêmica cujo objetivo é um embate sobre um tópico definido de modo claro. Houve indicação de problemas conceituais ou metodológicos em uma teoria, por exemplo, por meio da evidência construída em provas que sustentam rupturas. Uma troca polêmica sem possibilidade de solução, que revelava divergências profundas. Os embates de ideias não são considerados apenas como questão de erros a serem corrigidos, já que os contendores acumularam argumentos que acreditavam poder aumentar o valor de suas posições diante das objeções dos oponentes. Essa caracterização do debate é possível porque tanto Tarallo quanto Borges e Müller adotaram a desvalorização do outro, com indicações de erros, equívocos, falhas de compreensão, sem deixar de identificar argumentos problemáticos e mesmo ausência de conhecimentos básicos em algumas áreas que lhes pareciam pertinentes na defesa de sua retórica. Ao mesmo tempo, os posicionamentos no debate em alguns momentos se ampliaram para a abordagem de outros assuntos de algum modo relacionados com a polêmica instaurada.

Pertencer a grupos de especialidade distintos contribuiu, nesse sentido, para que a oposição se mostrasse de forma mais direta, e muitas vezes mais agressiva, pois, ao lado de um interesse em firmar espaços acadêmicos e intelectuais, havia também o pertencimento a comunidades argumentativas que sustentavam a legitimação dos grupos.

Tarallo, Borges e Müller falaram cada um do espaço que lhes parecia legitimado naquele momento, o que possibilitou que formulassem retóricas que não circularam apenas como artigos de periódico, mas sim como elementos-chave para identificar pertencimentos e exclusões (a grupos de pesquisa e a centros de ensino e produção científica) na configuração plural e receptiva da linguística brasileira da época.

18 O texto de 1989 foi republicado em coletânea de textos de Borges Neto em 2004. É a partir desta última edição que fazemos as referências. 
"A cada um convém uma coisa" - Aliud alios decere - é expressão usada pelo romano Quintiliano (35d.C.-100d.C.), para se referir às artimanhas do relativismo pessoal e do embate de ideias que procuram a razão nelas mesmas. As palavras latinas parecem ir ao encontro das posições relativas assumidas no debate aqui revisto. Posições essas que evidenciam o humano da ciência. Não só a cada um parecia convir algo no debate, como também as palavras também serviram de armas na busca pela validação das ideias. Talvez outra expressão seja até mais adequada a esse episódio: "As armas repelem-se com as armas" - Arma armis propulsantur -; expressão usada, entre outros, pelo cardeal grego Besarion (no século XV) e por Marco Ofarris (no século XVIII), em livro de orientações bélicas escrito na Itália em 1773 para soldados.

No debate, além de ideias, forças em oposição se mostraram de modo evidente nas retóricas em ação nas páginas da revista DELTA no final da década de 1980. Desse modo, é possível associar a noção de retórica de ruptura aqui adotada à noção de retórica do dissenso discutida por Amossy (2017). Essa retórica do dissenso estabelece discursos polêmicos que se caracterizam não pela possibilidade do debate e de um possível diálogo conciliador, mas pelo fechamento discursivo, no sentido de que os argumentos estabelecidos em um debate são de natureza altamente excludente, pautadas na desvalorização argumentativa do outro, que passa a ser o lugar por excelência a combater e não com quem contemporizar.

Uma polêmica, tal como a travada no debate aqui revisto historicamente, tem sua função social em um espaço público (no espírito da avaliação de AMOSSY, 2017 19 ), pois na retórica dos linguistas, como apontamos, havia vozes ecoando pertencimentos a grupos específicos e legitimações acadêmicas, consequentemente sociais.

Aceitar ideias linguísticas é também aceitar que posições em pesquisa e ensino sejam validadas, assim como assumir argumentos como os mais adequados em um determinado recorte social e temporal é configurar, mesmo que só tenhamos consciência disso retrospectivamente, um panorama de ação científica em uma sociedade. Nesse sentido, parte do que se compreende como a linguística brasileira hoje é também herdeira de momentos como o da polêmica aqui revista. Não à toa, Altman (1998), em sua avaliação histórica dos primeiros momentos da linguística brasileira, aponta movimentos de unificação e diversificação, nos quais, ao lado da prática científica, valeram também, em nossa interpretação, e de modo incisivo, as retóricas que asseguraram ou não espaços acadêmicos para aqueles que melhor souberam fazer valer a sua palavra.

\section{Conclusão}

Rever uma história é interpretar o passado, projetando nesse ir e vir dos tempos nossa própria visão a respeito de uma série de elementos que permitem reconhecimentos e oposições. Um processo dinâmico que faz com que a historiografia, o narrar e

19 "[...] a polêmica preenche funções sociais importantes, precisamente em razão do que é em geral criticado nela: uma gestão verbal do conflito realizada sob o modo da dissensão." (AMOSSY, 2017, p.12, grifo da autora). 
interpretar a história, não seja mera coleta de documentos e descrições, mas seja de fato construção de memória e imagens simbólicas.

A memória, e a identidade que dela é decorrente, pode ser compreendida como uma ação de reconstrução significativa de um passado. Nesse sentido, a questão para o historiógrafo não é tanto o que ele encontra num documento, mas como ele engendra explicações plausíveis para o que o documento oferece como evidências.

$\mathrm{Na}$ extensão deste artigo não nos é possível avançar mais em interpretações, mas é importante considerar que no debate do final da década de 1980 estava, para além da retórica, uma questão mais complexa: a identidade que a linguística brasileira iria definir para si mesma, em meio à pluralidade e à recepção de ideias que sempre foram suas características mais marcantes.

Além de tratar de conjunção de programas de investigação, a discussão travada entre os linguistas colocava no substrato de seus dizeres os rumos que poderia tomar uma ciência da linguagem feita no Brasil, com todas as variáveis que caracterizam a construção das identidades em um campo feito de legitimação e pessoalismos, quando se trata da validação e aceitação de práticas de pesquisa científica.

\section{Agradecimentos}

CNPq.

BATISTA, R. "To each one what seems best to her/him": Debate and controversy around the Parametric Sociolinguistics in the History of Brazilian Linguistics. Alfa, São Paulo, v.62, n.2, p.255-276, 2018.

- ABSTRACT: This article analyzes a debate in the Brazilian linguistics of the 1980s, when Fernando Tarallo, José Borges Neto and Ana Lúcia de Paula Müller differed on a parametric sociolinguistics. In the perspective of a study of the Historiography of Linguistics and based on a socio-rhetorical framework of analysis, which defines theoretical and methodological guidelines of this proposal, the text presents (i) considerations about what is understood in this interpretation as rhetoric and (ii) a historiographic analysis of the debate. This analytical view considers for its interpretative perspective discursive elements of the discourses adopted in the debate (that is, the rhetoric assumed by the linguists) and also elements of a social nature, that can circumscribe the discourses in specific groups of researchers (theory groups) in language science in Brazil. It is pointed out that the debate in question, several times referenced when it comes to a history of Brazilian linguistics, maintained its polemical nature, evidencing that the rhetoric of linguists, when assumed by the historiographic view, must be understood from of its social and historical inscription.

- KEYWORDS: Historiography of linguistics. Socio-rhetorical framework. Rhetoric. Brazilian linguistics. Parametric sociolinguistics. 


\section{REFERÊNCIAS}

ALTMAN, C. A pesquisa linguística no Brasil (1968-1988). São Paulo: Humanitas, 1998.

ALTMAN, C.; BATISTA, R. de O. (Org.). Dossiê historiografia da linguística. Todas as Letras: Revista de Língua e Literatura, São Paulo, v. 1, n. 14, p. 11-120, 2012.

AMOSSY, R. Apologia da polemica. Traduzido e coordenado por Mônica M. Cavalcante do orig. em francês de 2014. São Paulo: Contexto, 2017.

BARONAS, R. L. Ciências brasileiras da linguagem. Linguasagem, São Carlos, n. 19, 2012. Disponível em <http://www.letras.ufscar.br/linguasagem/edicao19/divcient/001. pdf>. Acesso em: 03 out. 2017.

BASTOS, N. B.; BATISTA, R. de O. Entre a história e a ciência: a constituição da Historiografia da Linguística como área de pesquisa e ensino nos estudos sobre a linguagem. In: SÁ Jr., L.; MARTINS, M. A. (Org.). Rumos da linguística brasileira no século XXI. São Paulo: Blucher, 2016. p. 57-71.

BATISTA, R. de O. Forma vs. Função na história da linguística brasileira: debates e retórica de ruptura: uma interpretação pela Historiografia da Linguística. Confluência: Revista do Instituto de Língua Portuguesa, Rio de Janeiro, n. 52, p. 9-32, 2017 a.

BATISTA, R. de O. Ideias linguísticas e sua história: modos de interpretar o conhecimento sobre a linguagem. In: VASCONCELOS, M. L. M. C.; BATISTA, R. de O.; PEREIRA, H. B. Estudos linguísticos: língua, história, ensino. São Paulo: Mackenzie, 2017b. v. 1. p. 175-184.

BATISTA, R. de O. A historiografia da linguística e a retórica dos linguistas: a força das palavras e seu valor histórico. Filologia e Linguística Portuguesa, São Paulo, n.18, v. 2, p. 301-317, 2016.

BATISTA, R. de O. Retórica de ruptura e descontinuidade nas ciências da linguagem: um estudo pela historiografia da linguística. Confluência: Revista do Instituto de Língua Portuguesa, Rio de Janeiro, n. 49, p. 119-141, 2015.

BATISTA, R. de O. Introdução à historiografia da linguística. São Paulo: Cortez, $2013 a$.

BATISTA, R. de O. Uma técnica, um grupo e uma retórica: a gramática construtural na história da linguística brasileira. Revista Letras, Curitiba, n. 87, p. 39-66, 2013b. Disponível em: < https://revistas.ufpr.br/letras/article/view/32039/22008>. Acesso em: 03 out. 2017.

BORGES NETO, J. Ensaios de filosofia da linguística. São Paulo: Parábola, 2004. 
BORGES NETO, J. M.; PAULA, A. L. de. Linguistas ou camaleões? uma resposta a Tarallo. DELTA, São Paulo, v. 1, n. 3, p. 85-95, 1987.

BORGES NETO, J. ; MÜller, A. L. P.; PIRES DE OLIVEIRA, R. A semântica formal das línguas naturais: histórias e desafios. Revista de Estudos da Linguagem, Belo Horizonte, v. 1, n. 20, p. 119-148, 2012.

COSERIU, E. Panorama da linguística ibero-americana. In: COSERIU, E. Tradição e novidade na ciência da linguagem. Tradução de C. A. Fonseca e M. Ferreira do original espanhol de 1977. São Paulo: EDUSP; Rio de Janeiro: Presença, 1980. p.277-368.

DUARTE, M. E. Avanço no estudo da mudança sintática associando a teoria da variação e mudança e a teoria de princípios e parâmetros. Caderno de Estudos Linguísticos, Campinas, n. 57, v. 1, p. 85-111, 2015.

FERREIRA, L. A. Leitura e persuasão: princípios de análise retórica. São Paulo: Contexto, 2010.

GROSS, A. G. The rhetoric of science. Cambridge: Harvard University, 1990.

KOERNER, E. F. K. Quatro décadas de historiografia lingüística: estudos selecionados. Pref. Carlos Assunção. Sel. e ed. de textos Rolf Kemmler e Cristina Altman. Vila Real: Centro de Estudos em Letras da Universidade de Trás-os-Montes e Alto Douro, 2014. (Coleção Linguística, v. 11).

MALUFE, J. R. A retórica da ciência: uma leitura de Goffman. São Paulo: Educ, 1992.

MURRAY, S. Theory groups and the study of language in North America: a social history. Amsterdam: John Benjamins, 1994.

PARREIRA, M. S. Ensaio sobre a compatibilização de teorias distintas: a sintaxe gerativa e a sociolinguística. Web-Revista Sociodialeto, Campo Grande, n. 15, p.351-359, 2015. Disponível em: <http://www.sociodialeto.com.br/edicoes/20/12062015125217.pdf>. Acesso em: 03 out. 2017.

PERELMAN, C.; OLBRECHTS-TYTECA, L. Tratado da argumentação: a nova retórica. Tradução de Maria Ermantina Galvão do original em francês de 1992. São Paulo: Martins Fontes, 1996.

PLANTIN, C. A argumentação. Tradução de Marcos Marcionilo do original em francês de 2005. São Paulo: Parábola, 2008.

POSTAL, P. M. Advances in linguistic rhetoric. Natural Language and Linguistic Theory, [S.1.], v. 6, n. 1, p. 129-137, 1988.

RAJAGOPALAN, K. Science, rhetoric, and the sociology of knowledge: a critique of Dascal's views of scientific controversies. In: WRIGLEY, M. (Ed.). Dialogue, language, rationality: a festschrift for Marcelo Dascal. São Paulo: CLE/Unicamp, 2009. p. 433-464. 
RAJAGOPALAN, K. O discurso científico, seus desdobramentos e seus embustes. In: GONÇALVES, A. G.; GÓIS, M. L. (Org.). Ciências da linguagem: o fazer científico. Campinas: Mercado de Letras, 2004. v.2. p. 7-23.

REBOUL, O. Introdução à retórica. Tradução de Ivone C. Benedetti do original francês de 1991. São Paulo: Martins Fontes, 2000.

SILVA, H. S. Sobre o alcance da sociolinguística no estudo da mudança paramétrica: uma perspectiva interlinguística. Working Papers em Linguística, Santa Catarina, n.13, v. 2, p. 47-65, 2013.

SWIGGERS, P. Linguistic Historiography: a metatheoretical synopsis. Todas as Letras: Revista de Língua e Literatura, São Paulo, v. 2, n. 19, p. 73-96, 2017.

SWIGGERS, P. A historiografia da linguística: objeto, objetivos, organização. Confluência: Revista do Instituto de Língua Portuguesa, Rio de Janeiro, n. 44-45, p.39-60, 2013.

SWIGGERS, P. Linguistic Historiography: object, methodology, modelization. Todas as Letras: Revista de Língua e Literatura, São Paulo, v. 1, n. 14, p. 38-53, 2012.

SWIGGERS, P. Another brick in the wall: the dynamics of the History of Linguistics. In: NOOTDEGRAAF, J. et al. (Ed.). Amicitia in academia: composities voor els elffers. Amsterdam: Stichting Neerlandistiek; Münster: Nodus, 2006. p. 21-28.

SWIGGERS, P. Modelos, metodos y problemas en la Historiografía de la Lingüística. In: ZUMBADO, G. C. et al. (Ed.). Nuevas aportaciones a la Historiografía Linguiística, actas del IC Congreso Internacional de la SEHL. Madrid: Arco Libros, 2004. p. 113-146.

TARALLO, F. Uma estória muito mal contada. DELTA, São Paulo, v. 2, n. 4, p. $265-$ 272, 1988.

TARALLO, F. Zelig: um camaleão-linguista. DELTA, São Paulo, v. 1, n. 2, p. 127 144, 1986.

TARALLO, F. Por uma sociolinguística românica "paramétrica": fonologia e sintaxe. Cadernos de Linguística e Teoria da Literatura, Belo Horizonte, n. 13, p. 51-83, 1985.

TARALLO, F.; KATO, M. Harmonia trans-sistêmica: variação inter- e intra-linguística. Revista Diadorim, Rio de Janeiro, v. 2, p.13-42, 2007. Disponível em: <https://revistas. ufrj.br/index.php/diadorim/article/view/3849/2827>. Acesso em: 03 out. 2017.

Recebido em 17 de setembro de 2017

Aprovado em 22 de março de 2018 